\title{
The impact of periventricular white matter lesions in patients with bipolar disorder type I - CORRIGENDUM
}

\author{
Gianluca Serafini, Maurizio Pompili, Marco Innamorati, Nicoletta Girardi, \\ Leonardo Strusi, Mario Amore, Leo Sher, Xenia Gonda, Zoltan Rihmer, and \\ Paolo Girardi
}

First published online 25 February 2014

doi:10.1017/S1092852913000825, Published by Cambridge University Press, online 10 January 2014.

In the original publication of "The impact of periventricular white matter lesions in patients with bipolar disorder type I' some errors appeared in the reference section. The following notes the necessary corrections to these errors:

- Within reference 1 "2002" should be "2002a"

- Within reference 2 "2002" should be " $2002 b$ "

- Within reference 17 "2012" should be "2012a"

- Within reference 25 "2008" should be " $2008 \mathrm{a}$ "

- Within reference 41 " 2003 " should be " $2003 \mathrm{a}$ "

- Citation 44 should instead be: Soares JC. Contributions from brain imaging to the elucidation of pathophysiology of bipolar disorder. Int $J$ Neuropsychopharmacol. 2003; 6(2): 171-180.
- Within reference 62 "2012" should be "2012b"

- Citation 64 should instead be: Alexopoulos GS, Meyers BS, Young RC, Campbel S, Silbersweig D, Charlson M. 'Vascular depression' hypothesis. Arch Gen Psychiatry. 1997; 54(10): 915-922.

- Within reference 65 "2008" should be " $2008 b$ "

- Within reference 82 "2003" should be "2003b"

The authors regret these errors.

\section{REFERENCE:}

Serafini G, Pompili M, Innamorati M, et al. (2014) The impact of periventricular white matter lesions in patients with bipolar disorder type I. CNS Spectrums, originally published online January 10, 2014. doi:10.1017/S1092852913000825. 